\title{
Seleção de portfólio de projetos na área de tecnologia da informação
}

Jairo Cardoso de Oliveira

Doutorando em Administração - PPGA Universidade Nove de Julho, com linha de pesquisa em Sustentatbilidade /Cidades Inteligentes. Mestre em Administração - Gestão de Projetos.Programa de Pós Graduação em Administração da Universidade Nove de Julho, São Paulo, Brasil jairo.oliveira13@gmail.com

Roque Rabechini Jr.

Doutor em Engenharia de Produção (Poli/USP). Professor do Progama de Pos Graduação em Administração na Universidade Nove de Julho.Programa de Pós Graduação em Administração da Universidade Nove de Julho, São Paulo, Brasil

roque@rabechini.com.br

\section{Editor Científico: José Edson Lara}

Organização Comitê Científico

Double Blind Review pelo SEER/OJS

Recebido em 10.02.2017

Aprovado em 03.04.2017

\footnotetext{
Este trabalho foi licenciado com uma Licença Creative Commons - Atribuição - Não Comercial 3.0 Brasil
} 


\title{
Resumo
}

Projetos de tecnologia da informação apresentam-se como fontes de obtenção de vantagem competitiva à medida que automatizam atividades e diminuem as variações dos resultados de processos produtivos. Essa característica tem aumentado a quantidade de projetos de $\mathrm{TI}$, mas muitos extrapolam a capacidade física e financeira das empresas em adquiri-los e implantá-los, sendo necessário um processo de seleção que sempre esteja ligado à dimensão estratégica e com critérios bem definidos. Métodos de seleção de portfólio foram desenvolvidos para responder à questão de como realizar essa priorização. $O$ foco deste estudo foi verificar a aderência desses métodos de seleção de projetos de TI à realidade de grandes empresas que empreendem esses projetos para sua própria utilização. $O$ método utilizado neste trabalho é o estudo de caso múltiplo, caracterizado por uma avaliação qualitativa. Os resultados alcançados apontam que o processo de seleção de projetos é feito em pelo menos duas etapas, utilizando o modelo de funil. Um aspecto importante evidenciado pela pesquisa, e que não foi verificado nos modelos teóricos, foi a necessidade de projetos que atendam a requisitos legais, comuns à área de $\mathrm{TI}$.

Palavras-chave: Gestão de Portfólio; Gestão de Projetos; Tecnologia da Informação; TI.

\section{Selection of projects portfolio in information technology area}

\begin{abstract}
Information technology projects are presented as sources of obtaining competitive advantage as they automate activities and reduce the variations of the results of productive processes. This feature has increased the amount of IT projects placed for the evaluation of companies, which extrapolate the physical and financial capacity to undertake them, requiring a selection process that is always linked to the strategic dimension and has defined criteria for it. Portfolio selection methods were developed to answer the question of how to carry out this prioritization. The focus of this study verified the adherence of theoretical methods of selecting IT projects to the reality of large companies that undertake IT projects for their own use. The method used in this work is the multiple case study, characterized by qualitative evaluation. The results obtained show that the project selection process is done in at least two stages, using the funnel model. An important aspect verified in the research that was not verified in the theoretical models is the need to attend projects that meet legal requirements common to the IT area.
\end{abstract}

Keywords: Portfolio Management; Project Management; Information Technology; IT. 


\section{Selección de portales de proyectos en el área de tecnología de la información}

\section{Resumen}

Los proyectos de tecnología de la información se presentan como fuentes de obtención de ventaja competitiva en la medida que automatizan las actividades y disminuyen como variaciones de los resultados de procesos productivos. Esta característica ha aumentado una cantidad de proyectos de TI para una evaluación de las empresas, que extrapolan una capacidad física y financiera de emprender-los, siendo necesario un proceso de selección que sintetizan el tamaño del mapa estratégico y que los resultados determinaron para tal. Métodos de selección de portafolios han sido desarrollados para responder a la pregunta de cómo realizar esta priorización. O foco de este estudio verifico una adherencia de los métodos teóricos de la selección de proyectos de TI en la realidad de las grandes empresas que realizan proyectos de TI para su propia utilización. El método utilizado en este estudio es el estudio de caso múltiple, caracterizado por la evaluación cualitativa. Los resultados alcanzados por el proceso de selección de proyectos se realizan en menos de dos etapas, utilizando el modelo de diseño. Un aspecto importante de verificación en la investigación y que no se ha verificado en los modelos teóricos es una necesidad de servicios que se prestan a los servicios legales, comunes al área de TI.

Palabras clave: Gestión de Portfólio; Gestión de Proyectos; Tecnología de la Información; TI.

\section{Introdução}

O desenvolvimento da tecnologia da informação e das comunicações é um fator de transformação na economia e na forma de realizar negócios. A interação entre a tecnologia da informação, a economia e os negócios criou termos que atualmente são de utilização comum, como e-commerce, e-economy e e-business (Molla, Pittayachawan, Corbitt, \& Deng, 2009). A TI é também uma das áreas que mais empreende projetos. Em pesquisa do PMSURVEY.ORG, vinculado aos capítulos do PMI (Project Management Institute), a área de TI desponta como a que mais utiliza metodologias de gestão de projetos e a que conta com o maior número de PMOs (Project Management Offices ou Escritórios de Projetos) (PMSURVEY, 2013). Neste cenário, é comum que existam mais projetos para serem realizados do que a efetiva capacidade física e financeira de empreendê-los, de tal forma que uma escolha entre os mesmos tenha que ser realizada (Archer \& Ghasemzadeh, 1999). 
A seleção de portfólio de projetos é objeto de investigação de inúmeros autores, com a proposição de modelos teóricos que avaliam não somente seleção de projetos, mas também produtos (Clark \& Wheelwright, 1993; Archer \& Ghasemzadeh, 1999; Cooper, Edgett, \& Kleinschmidt, 1999; Ghasemzadeh \& Archer, 2000; Cooper, 2008; Garcez \& Maccari, 2015). Alguns artigos apresentam estudos empíricos sobre indústrias específicas (Rabechini Jr, Maximiano, \& Martins, 2005; Padovani, Muscat, Camanho, \& Carvalho, 2008; Padovani, Carvalho, \& Muscat, 2010). Apesar da relevância do tema gestão de portfólio em TI, poucos trabalhos conjugam os dois construtos em uma pesquisa empírica, com menção ao trabalho desenvolvido por Reyck, Grushka-Cockayne, Lockett, Calderini, Moura, \& Sloper (2005) em pesquisa quantitativa com 31 empresas do Reino Unido.

O objetivo deste estudo é levantar na literatura características importantes para comparar projetos dentro do portfólio e verificar o uso destas em portfolios da área de $\mathrm{Tl}$. O estudo se realizou em seis empresas com a área $\mathrm{TI}$, caracterizando-o como estudo de caso múltiplo, cujos dados foram coletados por meio de entrevistas semiestruturadas com os responsáveis. Assim, este artigo busca responder à seguinte questão de pesquisa: Como organizações de $\mathrm{Tl}$ utilizam conceitos de gestão de portfólio para selecionar seus projetos?

Como resultado, foi possível avaliar de forma mais profunda as possíveis características da área de TI que podem diferenciá-la de outras áreas, no que se refere à gestão de portfólio, e servir de base para comparação e tomada de decisão. A contribuição mais importante deste estudo é o levantamento de características de portfólio de projetos na literatura e a comparação do uso destas características nas empresas na área de $\mathrm{TI}$, caracterizando, assim, a área de $\mathrm{Tl}$ e como nela se dá o tratamento da gestão de projetos.

\section{Revisão da Literatura}

A revisão da literatura traz o embasamento dos principais conceitos abordados neste trabalho. A pesquisa teórica realizada teve como eixos principais a gestão de projetos e portfólio e a importância estratégica da TI. 


\subsection{Gestão de Projetos e Portfólio}

A gestão de projetos passou por inúmeras transformações até ser considerada como processo de negócios, e não mais apenas uma gestão de projetos (Kerzner, 2009). Para isso, uma organização pode ter suas atividades divididas nas categorias de operações e projetos (Shenhar \& Dvir, 2010). Enquanto a primeira categoria atua de forma repetitiva e contínua, projetos servem como elementos propulsores de inovação e mudanças, necessários para que as empresas respondam ao desafio da globalização.

A transformação pela busca de melhorar competitividade e posicionamento de mercado tem na inovação um caminho diferente dos métodos gerenciais tradicionais, reforçando a necessidade de investimento em técnicas de gestão de projetos (Carvalho \& Rabechini Jr., 2015). A tendência da gestão de projetos é mudar de uma abordagem mais tradicional para uma abordagem na qual o gestor busca atingir os resultados de negócios em que o projeto foi empreendido. Como abordagem tradicional entende-se o projeto realizado de acordo com as restrições já pré-definidas (Shenhar, 2004).

A gestão de projetos se concentra em realizar os projetos de forma correta, enquanto a Gestão de Portfólio de Projetos (GPP) tem como finalidade realizar os projetos certos (Reyck et al., 2005). A gestão de projetos tem como foco um projeto único, enquanto a GPP considera a carteira com todos os projetos empreendidos pela organização, definindo prioridades e decidindo quais projetos devem ser incluídos ou excluídos da carteira.

A escolha da carteira de projetos deve estar ligada à dimensão estratégica da organização, característica da segunda onda da gestão de projetos. Esta onda tem foco na eficácia e geração de resultados consistentes e sucede o foco na introdução de métodos de gestão de projetos. Os projetos são caracterizados por investimentos em treinamentos e certificações (Rabechini Jr et al., 2005). A gestão desses projetos 
deve ser rigorosa, e as decisões e sua organização podem influenciar o desempenho dos projetos (Schneider, Barbosa, Bouzada, \& Gonçalves, 2016).

Fazer escolhas estratégicas sobre os projetos a serem empreendidos por uma organização, alocar os recursos disponíveis e necessários para a sua implantação, bem como balancear estes recursos entre os projetos empreendidos é o de que trata a gestão de portfólio (Cooper et al., 1999). Importante também é trabalhar ou analisar os projetos, agrupando-os de acordo com cada atividade ou área distinta (Garcez \& Maccari, 2015)

O alinhamento estratégico pode ser obtido através de "uma adequada gestão de carteira (portfólio) de projetos, da implantação de uma estrutura apropriada (estratégica) na forma de escritórios de projetos e da construção de competências e de maturidade em gestão de projetos em âmbito organizacional" (Rabechini Jr et al., 2005, p. 417). Já a seleção de um portfólio de projetos é “a atividade periódica envolvida na seleção de um portfólio de projetos, que atende os objetivos definidos da organização, sem exceder os recursos existentes ou violar outras restrições" (Ghasemzadeh \& Archer, 2000, p. 1).

Métodos de gestão de portfólio foram desenvolvidos para responder à questão de quais projetos selecionar. Estudos apontam que a definição de modelos de seleção de portfólio, originais das décadas de 1960 e 1970, eram baseados em modelos matemáticos (Cooper et al., 1999). Estes, porém, não eram práticos devido à necessidade de disponibilizar um grande volume de informações, que nem sempre estava à mão ou não continha o grau de acuracidade necessário. Além desses, fatores como análise de riscos e incertezas e a dificuldade de avaliar relações cruzadas levaram este método ao desuso (Cooper et al., 1999).

Outros métodos foram utilizados para a seleção de projetos de um portfólio, entre os quais se destacam: modelos financeiros e índices financeiros; modelos probabilísticos financeiros; teoria de opções de precificação; abordagens estratégicas; modelos de pontuação e checklists; abordagens de análise hierárquica; abordagens comportamentais; processos de análise e diagrama de bolhas (Cooper et al., 1999). Dentre estes, os métodos financeiros, métodos de estratégia de negócios, diagramas de bolha, modelos de pontuação e checklists são apontados como os mais populares na seleção de portfólio. 
As dificuldades para a seleção de portfólio de projetos têm origem nos seguintes fatores: existência de objetivos múltiplos e quase sempre conflitantes; natureza qualitativa de parte dos objetivos; existência de incertezas e riscos podem afetar projetos; balanceamento de importância de fatores como risco e prazo no portfólio selecionado; interdependência entre projetos e; grande número de portfólios viáveis (Ghasemzadeh \& Archer, 2000).

É preciso implantar uma ferramenta para facilitar a escolha de quais produtos precisam ser trabalhados (Clark e Wheelwright, 1993, como citado em Gavira, et al., 2007, p. 86). Esta ferramenta é conhecida como funil da inovação. Nela é agregado o conceito de reduzir o número de ideias (ou projetos), mantendo as que apresentam maior probabilidade de sucesso.

A ferramenta propõe um processo em fases distintas e sequenciais, com avaliação ao final de cada uma delas, permitindo que somente as ideias que atendam aos critérios estabelecidos previamente possam avançar. Para seleção de ideias que vão se transformar em projetos, e finalmente em produtos, são utilizados cinco elementos, que vão desde o início ou boca do funil até o final ou cauda (Gavira et al., 2007). Cada elemento deve, ao seu final, apresentar uma decisão de prosseguir ou não com a ideia ou projeto.

A mente humana tem limitações para considerar todos os fatores envolvidos no processo de tomada de decisão e ainda seus efeitos. De forma simultânea "tipicamente indivíduos fazem escolhas em uma base reativa e muitas vezes não planejada, com pouca avaliação de como unir as decisões para formar um plano integrado" (Saaty, 1988, p.109). O processo de definição de escolhas deve ser feito por meio de uma organização que utilize representação hierárquica, na qual sejam integrados processo de julgamento e análise de medidas (Saaty, 1988).

O processo hierárquico de análise (AHP - Analytic Hierarchy Process) é um modelo de decisão que utiliza recursos matemáticos, como a álgebra linear (Saaty, 1988). É uma ferramenta que apresenta desempenho rápido com resultados úteis na tomada de decisão na presença de critérios qualitativos e quantitativos (Padovani et al., 2010).

Essa ferramenta é entendida como um conceito de medida e leva em 
consideração a comparação de fatores necessários para derivação de escalas normalizadas com números absolutos "cujos elementos são então utilizados como prioridades, e podem ser aplicadas a ambos os critérios tangíveis e intangíveis com base nos julgamentos de pessoas conhecedoras e especialistas" (Saaty, 2007, p. 860).

A ferramenta AHP permite que o objetivo geral seja decomposto em critérios específicos, que podem ser escolhidos e ter seus pesos atribuídos por uma técnica de comparação em pares. Podem, assim, serem definidos critérios, subcritérios e outros níveis. Em um estudo que envolveu seis organizações, entre públicas e privadas, critérios como complexidade, riscos, expectativas de retorno de investimento para as partes interessadas e viabilidade técnica foram considerados como critérios de decisão universais para seleção e priorização de projetos (Liu, Hsu, Yeh, \& Chen, 2011; Padovani, Muscat, Camanho, \& Carvalho, 2008).

A ferramenta AHP é apropriada para casos em que os critérios utilizados para julgamento e peso são independentes entre si. Nos casos em que estes sejam dependentes entre si, o processo analítico de rede (ANP - Analytic Network Process) é o mais indicado. Pode-se citar como exemplo de um processo no qual os critérios são interdependentes uma análise de impacto ambiental, na qual os critérios seriam poluição ambiental, alteração ecológica e perturbação socioeconômica (Liu et al., 2011).

Assim, o desenvolvimento socioeconômico pode produzir poluição ambiental e causar alterações ecológicas. Por outro lado, a poluição do ambiente e alterações ecológicas também impactam o desenvolvimento da sociedade, incluindo seus aspectos econômicos. Portanto, os critérios são dependentes entre si, de tal forma que sua análise deve ser feita em rede e não em hierarquia (Liu et al., 2011).

\subsection{A importância estratégica da TI}

A $\mathrm{Tl}$ teve seu posicionamento alterado no organograma das organizações, passando de uma função tradicionalmente corporativa (de back office) para assumir um papel estratégico não somente no tocante aos negócios existentes, mas com potencial de mudar as estratégias de negócios (Henderson \& Venkatraman, 1993). 
Albertin (2001) defende que várias alterações que ocorrem no ambiente de negócios são derivadas da evolução da $\mathrm{TI}$, seja pela ação de novas tecnologias, seja pela ação de novas aplicações. Ainda neste contexto, a TI atua modificando as bases de competitividade estratégicas e operacionais das organizações.

De acordo com Nolan \& McFarlan (2005), os comitês de diretores das organizações perceberam o impacto que a $\mathrm{TI}$ tem sobre suas empresas a partir do receio de colapso que veio com a transição do ano 2000. Segundo os autores, devido à falta de uma linha de governança corporativa focada em TI e da falta de conhecimento básico destes gestores, não somente aspectos como riscos e custeio da TI, mas também aspectos de riscos competitivos são muitas vezes simplesmente desconsiderados. A busca de conhecimento de TI pelos administradores das organizações tem sido cada vez mais intensa, demonstrando que o conhecimento do mundo da tecnologia é essencial, pela dependência que as empresas têm da $\mathrm{TI}$ (Albertin, 2001).

A partir de uma análise de diversos modelos, Laurindo, Shimizu, Carvalho, \& Rabechini Jr (2001) concluem que o papel da TI no aspecto estratégico das organizações vem crescendo no quesito complexidade, ocasionado pelas oportunidades que a $\mathrm{Tl}$ oferece, em especial para empresas que atuam com a Internet. Como ponto comum entre todos os modelos analisados pelos autores, a visão estratégica deve ser avaliada tanto para o negócio quanto para a TI que, como indutora de vantagem competitiva, deve ser analisada em seu nível de gestão e não apenas em aplicações específicas. Outro ponto comum obtido a partir da análise dos autores refere-se à importância que deve ser atribuída aos aspectos organizacionais e aos aspectos técnicos, de forma a avaliar as novas disponibilidades técnicas em função do modelo de negócio, na busca de obter eficácia e não somente eficiência.

Para Albertin \& Albertin (2008), "os esforços organizacionais para a assimilação e utilização de TI são realizados na forma de projetos de TI" (p. 608). Os projetos de TI são dependentes do ambiente em que são empreendidos, com características próprias relativas a cada organização, que necessitam ser entendidas e planejadas, sendo improvável a replicação de processos de um projeto para outro (Albertin, 2001). Segundo Brusamolin \& Moresi (2008), a resistência criada para implantar mudanças no sistema de trabalho da organização faz com que o gerente 
de projetos de TI necessite desenvolver métodos para tratar este ambiente marcado por mudanças e por aprendizado constante.

\section{Método}

Este estudo visa avaliar casos relacionados às áreas de $\mathrm{Tl}$ e como essas áreas atuam na seleção de seus projetos de TI. O estudo visa demonstrar as principais características que são utilizadas no momento de tomada de decisão na gestão do portfólio de projetos. Para tanto, em um primeiro momento foi importante a utilização da pesquisa bibliográfica e pesquisa documental.

O método escolhido foi o de estudo de caso múltiplo, de caráter exploratório. Foram selecionadas por conveniência seis grandes empresas representando diferentes setores de atuação e com origens também distintas. A Tabela 1 apresenta as empresas participantes deste estudo de caso. As empresas que preferiram não divulgar seus nomes serão conhecidas apenas pela numeração atribuída

\section{Tabela 1}

Relação de casos

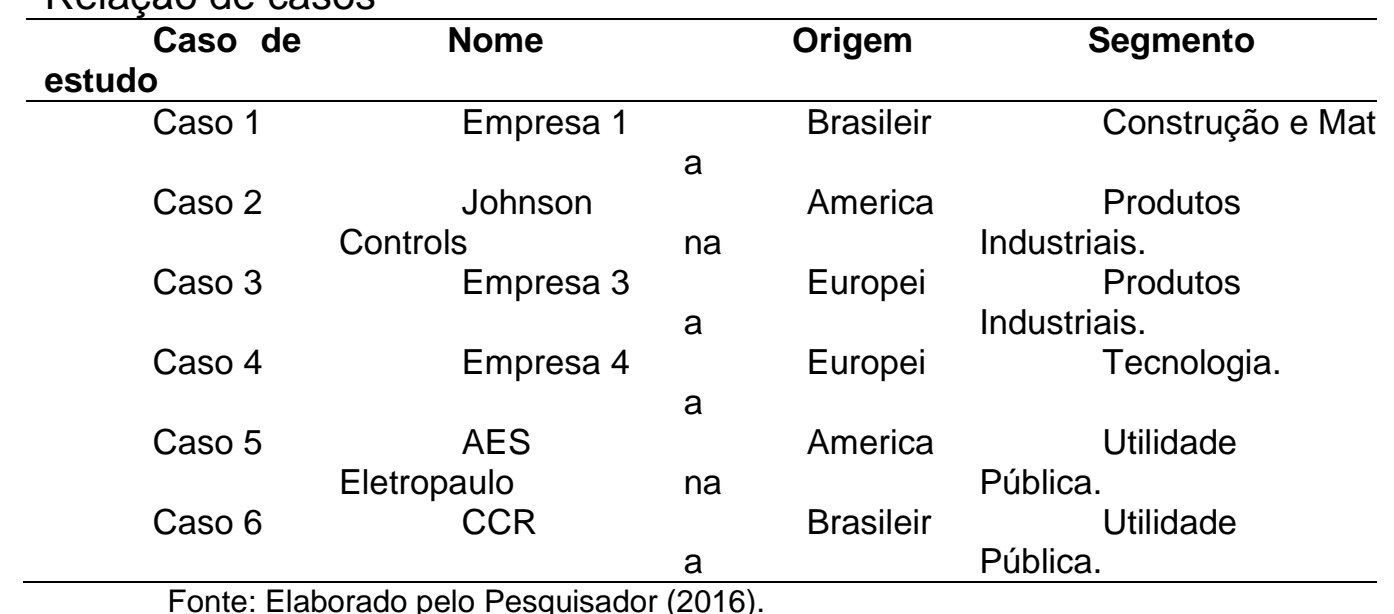

Considerando a área de $\mathrm{TI}$ dos quatro casos de empresas com origem fora do Brasil, três estão atreladas fortemente a programas corporativos mundiais, enquanto o grupo AES apresenta uma maior liberdade para definir as necessidades de TI nas operações no Brasil. As empresas brasileiras expandiram seus negócios para outras partes do mundo, podendo ser consideradas multinacionais de origem brasileira. A 
Empresa 4 tem a caraterística de ter a TI como seu negócio final, fornecendo serviços para outras. Já o Grupo CCR tem sua própria empresa de TI, a CCR EngelogTec, que provê serviços de TI para as demais empresas do grupo.

A outra fonte de dados deste trabalho foram as entrevistas realizadas com representantes das empresas selecionadas. Nesta pesquisa foi utilizada a entrevista semiestruturada com os responsáveis pela seleção de portfólio de projetos de TI, em cada uma das seis empresas que fizeram parte deste estudo. $O$ roteiro de entrevista foi composto de três partes. A primeira parte do formulário de pesquisa (Parte A Identificação da empresa e do entrevistado / Condições da entrevista) visa caracterizar as qualificações do entrevistado e sua posição na empresa. A segunda parte do formulário de pesquisa (Parte B - Gestão de Portfólio) apresenta perguntas abertas e tem o objetivo de avaliar o conhecimento do profissional na gestão de portfólio.

O estudo do caso 1 teve como entrevistado o gerente de TI, com formação em Processamento de Dados, atuando na empresa por 27 anos e ocupando esta função há 10 anos. O objeto de estudo do caso 2 é a área de TI da Johnson Controls, divisão Building Efficiency, tendo sido entrevistada a gerente de TI, Fernanda Reikdal Lima, que é formada em Administração de Empresas, trabalhando há 12 anos na Johnson Controls. Fernanda é a responsável pela área de $\mathrm{TI}$ da empresa no Brasil há cinco anos. $O$ estudo de caso 3 contou com o gerente de infraestrutura de $\mathrm{TI}$, que é matemático e trabalha na empresa há 35 anos, sempre na área de $\mathrm{TI}$, ocupando a atual função há dois anos.

Para o estudo de caso 4 foi entrevistado o Chief Information Officer $(\mathrm{ClO})$, que é formado em jornalismo, com mestrado em redes de computadores. Atua na empresa há 13 anos, sendo dois anos nesta função. Foi responsável pelas áreas de suporte a data center, service desk, networking e telecomunicações. Atualmente responde pela governança e gestão de projetos de TI. Antes de atuar na Empresa 4, atuou como consultor em outras organizações. Este profissional é responsável não somente pela organização no Brasil, mas seu raio de ação abrange a América Latina. A AES Eletropaulo é o objeto de estudo do caso 5 . O entrevistado do caso 5 é o Gerente de Infraestrutura de TI, Sérgio de Gouvea Costa, que é engenheiro civil, formado em 1977, atua na organização há 12 anos, sempre na mesma função. 
Antes de atuar na AES Eletropaulo, trabalhou na IBM. O entrevistado é responsável não somente pela AES Eletropaulo, mas tem função corporativa, compreendendo todas as empresas do grupo no Brasil. O caso 6 tem a CCR como objeto de estudo e contou com a entrevista de André Costa, funcionário da CCR EngelogTec. André é engenheiro da computação, atua no grupo há dez anos e está nesta função há um ano.

A abordagem da pesquisa descrita neste artigo é de natureza qualitativa, portanto utiliza as etapas de redução, exibição e conclusão/verificação (Gil, 2012). A etapa de redução, caracterizada pela seleção e simplificação dos dados, redundando em sumários organizados, neste trabalho é baseada na pesquisa documental e entrevistas realizadas para cada empresa, de forma a relatar brevemente os seguintes itens: Perfil da empresa; Perfil dos entrevistados; Descrição do processo utilizado para a seleção de projetos de infraestrutura de TI.

A etapa de exibição ou apresentação busca realizar uma análise sistemática das diferenças e semelhanças, bem como o inter-relacionamento dos dados. As análises comparativas com base nos dados obtidos entre empresas participantes do estudo são realizadas utilizando-se como foco os processos de seleção de projetos.

\section{Resultados}

Neste capítulo são apresentados os resultados da pesquisa documental de cada caso analisado, bem como os dados obtidos durante os processos de entrevista.

\section{Caso 1}

O estudo de caso 1 avalia a área de TI da Empresa 1, uma organização multinacional de origem brasileira, com operações em países das Américas, Europa e Ásia.

A empresa atua no fornecimento de commodities para as indústrias da construção e automotivas, além de atender segmentos de óleo e gás, energia eólica, 
máquinas e equipamentos agrícolas, mineração, entre outros. O grupo é composto por três empresas de capital aberto, com ações negociadas na BM\&F Bovespa e na New York Stock Exchange (NYSE).

O grupo conta com diversas unidades de produção, escritórios comerciais, terminais portuários corporativos e ainda produz energia elétrica para alimentar algumas dessas unidades. Essas unidades encontram-se localizadas em diversos países da América Latina além de outras localizadas nos Estados Unidos, Canadá, Europa e Ásia.

A área de $\mathrm{TI}$ da Empresa 1, objeto do estudo de caso, conta com um profissional de $\mathrm{Tl}$ alocado em cada área de negócio, atuando junto aos gestores destas áreas para avaliar as necessidades de sistemas, aplicações e recursos. Este representante tem papel destacado na captura e descrição inicial dos candidatos a integrarem a lista de projetos selecionados.

O caso 1 caracteriza-se pela adoção de modelo de terceirização para os serviços de data center e um modelo híbrido dos equipamentos de usuários (microcomputadores), ou seja, a Empresa 1 tanto adquire diretamente estes equipamentos, quanto exercita a terceirização por meio de contratos de locação com empresas especializadas.

De acordo com o entrevistado, o processo de seleção de projetos de TI é realizado com frequência anual, sendo iniciado pelos representantes da área de $\mathrm{Tl}$, alocados nas áreas de negócios. Esta fase é realizada até o mês de Setembro de cada ano, quando os estudos preliminares são encaminhados para a área de $\mathrm{TI}$ corporativa. A relação consolidada de candidatos a projetos passa por um processo de priorização, a fim de gerar uma lista de classificação global. Os principais critérios que são utilizados nesta fase e que tem pesos diferentes são os seguintes:

- Aderência ao plano estratégico estabelecido;

- Critérios financeiros, como retorno do capital investido e análise de custo benefício e;

- Obrigações legais.

A lista de classificação global de projetos é debatida e validada pela área corporativa de TI, que inclui os representantes de TI das áreas de negócios. Esses 
representantes informam aos gestores das áreas de negócios sobre os candidatos selecionados, com o objetivo de dar conhecimento dos candidatos aprovados e permitir o ajuste de orçamento.

O entrevistado comentou que, caso existam conflitos entre a lista de projetos validada e necessidades estratégicas ou políticas das áreas de negócios que porventura não tenham sido contempladas, o $\mathrm{ClO}$ (Chief Information Officer) é acionado para discussões em nível de diretoria da empresa a fim de obter a consolidação de uma lista final.

Revisões são realizadas, podendo a lista de projetos ser alterada caso não sejam confirmados os estudos técnicos iniciais que definiram a necessidade de recursos ou complexidade dos candidatos escolhidos. Nesta situação, projetos podem ser reavaliados, postergados ou até mesmo cancelados.

O processo de seleção de projetos deste estudo de caso apresentou características do modelo de funil, conforme defendido por Clark e Wheelwright (1993). Os critérios de sustentabilidade são utilizados na fase inicial da seleção, quando os projetos são debatidos no plano técnico para serem apresentados para a área corporativa de $\mathrm{TI}$.

\section{Caso 2}

O caso 2 avaliou a área de TI da Johnson Controls, uma empresa de origem norte americana, que conta com cerca de 170.000 funcionários no mundo.

A empresa foi fundada em 1885 em Wisconsin, Estados Unidos, a partir da invenção do termostato elétrico. Hoje atua com duas divisões de negócios:

- Power Solutions: Fabricante de baterias automotivas, sob as marcas Heliar, Varta e Optima. A empresa foi a primeira a desenvolver baterias de íon lítio para produção de veículos elétricos;

- Building Efficiency: Fornece sistemas de ar condicionado (residenciais e empresariais) e de automação predial, soluções de segurança e detecção e incêndio, refrigeração industrial e serviços de manutenção.

Para este trabalho, a pesquisa foi realizada com a área de $\mathrm{TI}$ da divisão Building Efficiency. Esta empresa realiza atividades relacionadas ao ambiente de $\mathrm{TI}$ 
majoritariamente de forma interna. O data center, de pequeno porte, não é terceirizado e os equipamentos de usuários (notebooks) são adquiridos diretamente pela empresa. Apenas as impressoras são terceirizadas.

Os projetos de seleção de $\mathrm{TI}$ do caso 2 , de acordo com a entrevistada, são estruturados a partir das demandas das áreas de negócios. A partir da identificação desta demanda, a área de $\mathrm{TI}$ executa uma avaliação dos candidatos, considerando os seguintes fatores:

- Impacto nos objetivos e estratégia da empresa;

- Complexidade;

- Departamentos afetados e;

- Relação custo versus benefício.

Os projetos candidatos são então dispostos em uma matriz ponderada e categorizados em:

- Small Change: pequena mudança, normalmente necessita de poucos recursos e não causa impacto em outras áreas que não a demandante;

- Small Project: projeto de pequeno porte;

- Enhancement: mudança em sistema existente, que exige uma quantidade razoável de recursos e pode impactar em mais de uma área e;

- Project: projeto de médio/grande porte.

O processo de seleção é realizado de acordo com a categoria do projeto e em níveis de aprovação. O primeiro nível é composto pela gerente de $\mathrm{TI}$ e os diretores de área Brasil. O segundo nível é composto pelo diretor de TI América Latina, Gerente de Aplicação América Latina, Gerente de Governança e PMO América Latina. Os candidatos de maior impacto podem requerer a aprovação do $\mathrm{ClO}$ (Chief Information Officer) da divisão mundial.

O processo de seleção de projetos pode receber revisões devido a mudanças de prioridades apontadas pela própria área demandante ou então por falta de definições detalhadas durante a execução de um projeto. A avaliação é mensal, desde que demandada por solicitações das áreas. 


\section{Caso 3}

O objeto de estudo do caso 3 é a área de TI da Empresa 3, que se trata de uma empresa multinacional do setor de tecnologia. A Empresa 3 está presente em mais de 180 países, contando com cerca de quatrocentos mil funcionários. No Brasil, o grupo possui mais de nove mil funcionários, distribuídos em oito empresas, que conta com 14 fábricas, 7 centros de desenvolvimento e escritórios regionais. A área de TI presta serviços para todas as empresas do grupo, terceirizando os serviços de data center, mas mantém o parque de microcomputadores em seu ativo. A área é considerada suporte para os negócios principais do grupo.

$\mathrm{Na}$ gestão de portfólio de projetos de $\mathrm{Tl}$, o processo é caracterizado por três fases distintas: levantamento de demanda, consolidação de demanda pelos critérios de seleção e seleção do portfólio. Todos os candidatos a projetos devem estar em sintonia com a estratégia da organização para serem considerados no processo de seleção de portfólio.

A primeira fase inicia-se com reuniões individuais entre os representantes de cada área de negócios ou área central e o representante da área de tecnologia da informação. Esta fase, que ocorre nos primeiros meses do ano, coleta a necessidade de novos processos ou ferramentas (demanda), em entrevista estruturada, na qual são avaliados:

- Quais áreas estão envolvidas na demanda (uma única área, mais de uma área, etc.);

- Descrição detalhada do problema e abordagem da solução pela perspectiva do negócio;

- Avaliação de retorno do investimento, tanto em valores monetários quanto em períodos de tempo;

- Estimativa de riscos;

- Alinhamento às regras internas da empresa;

- Sinergias e interoperabilidades.

$\mathrm{Na}$ segunda fase todas as demandas internas são consolidadas e são incluídos os projetos corporativos informados pela matriz da organização. O gerente de infraestrutura e o gerente de sistemas são os responsáveis por esta atividade e avaliam sinergias, possíveis conflitos e pontos impeditivos, consolidando uma 
planilha com todos os projetos que serão submetidos ao comitê da diretoria executiva.

A terceira fase, ou seja, a seleção de portfólio, avalia os candidatos a projetos em um processo de funil, como apresentado por Clark e Wheelwright (1993). O primeiro ponto de decisão avalia se as demandas foram geradas por projetos corporativos da matriz, seguido por projetos que atendam exigências legais ou fiscais. Segundo o entrevistado da área de $\mathrm{Tl}$, esses projetos são sempre implantados.

O segundo ponto de decisão avalia se os projetos são requeridos em virtude de esgotamento do ciclo de vida do produto. No caso desta organização, o ciclo de vida do produto é restrito ao software, uma vez que a organização atua no modelo de terceirização de ativos e serviços. Microcomputadores e outros equipamentos de usuário são avaliados pelas gerências funcionais e incluídos em sua previsão de custos para efeito de elaboração de orçamento, também sendo excluídos deste processo. Este segundo ponto de decisão nem sempre habilita os projetos a serem executados, pois existe a busca de alternativas para estender este ciclo de vida (extensão de garantia e extensão de suporte).

Esgotadas essas categorias de projetos, são avaliados todos os demais candidatos a projetos pelos critérios de retorno financeiro e de investimento, retorno em períodos de tempo e avaliação de risco. Os projetos são então agrupados em três categorias: projetos preferenciais (preferred projects), projetos interessantes, mas que não tem prioridade (nice to have projects) e finalmente projetos descartados (discharged projects). Havendo recursos, tanto financeiros quanto humanos, os projetos preferenciais que apresentarem os maiores retornos serão os escolhidos. Os projetos nice to have somente serão executados caso projetos preferenciais tenham que ser interrompidos e os projetos descartados definitivamente não sejam empreendidos. Os projetos selecionados neste processo serão implantados ao longo do ano seguinte.

A Tabela 2 resume os pontos de decisão utilizados na terceira etapa do processo de seleção de projetos de TI da organização. 


\section{Tabela 2}

Pontos de decisão de seleção de projetos do caso 3

\begin{tabular}{c|c}
\hline Ponto de decisão & Avaliação \\
\hline $1^{\circ}$ nível & $\begin{array}{c}\text { Projetos corporativos da matriz } \\
\text { Projetos que atendam requisitos } \\
\text { legais/fiscais }\end{array}$ \\
\hline $\mathbf{2}^{\text {a nível }}$ & Obsolescência tecnológica mandatória \\
\hline $\mathbf{3}^{\circ}$ nível & Retorno financeiro e de investimento \\
\hline $\mathbf{4}^{\circ}$ nível & Retorno em tempo \\
\hline $5^{\circ}$ nível & Estimativa de risco \\
\hline
\end{tabular}

Fonte: Elaborado pelo Autor a partir da entrevista com o gerente de infraestrutura de TI da Empresa 3 (2016).

\section{Caso 4}

A Empresa 4 tem na Tl o seu negócio fim, entretanto o objeto deste caso 4 se concentra nas suas necessidades internas de soluções de TI. É uma empresa multinacional do setor de tecnologia da informação, que atua tanto no desenvolvimento de aplicações quanto no atendimento a seus clientes no modelo de provedor de serviços de TI. Presente em 47 países e contando com mais de 75 mil funcionários (sendo cerca de 60 mil engenheiros), a empresa atende clientes dos mercados de manufatura, varejo e serviços, setor público, saúde e transporte, serviços financeiros, telecomunicações, mídia e tecnologia, energia e utilidades.

A área de $\mathrm{Tl}$, objeto deste estudo de caso, está estruturada a partir de definições corporativas da matriz e "adquire" serviços das áreas de negócios para suprir suas próprias necessidades como, por exemplo, serviços de data center e aquisição de equipamentos de usuários.

Roteiros (rodmaps) previamente definidos pela matriz estabelecem as linhas mestras dos projetos de $\mathrm{TI}$ da empresa do caso 4, tanto para projetos corporativos, de abrangência mundial, quanto para projetos que atendam às necessidades regionais e locais.

No âmbito regional/local, os projetos candidatos são discutidos com as áreas 
de negócios e são divididos em:

- Projetos que atendem as exigências oriundas da legislação, considerados os aspectos de cada país e;

- Projetos que tenham como objetivo melhoria de eficiência e redução de custos.

O entrevistado da área de $\mathrm{TI}$ interna $(\mathrm{ClO})$ apontou que a disponibilidade de recursos é um fator sempre considerado na análise de candidatos a projetos. Um exemplo apresentado pelo $\mathrm{CIO}$ foi a implantação de uma instância global de ERP, que depende de recursos que são mobilizados de região a região.

As prioridades, em resumo, estão apresentadas na Tabela 3.

\section{Tabela 31}

Tipos de projetos avaliados no caso 4

\begin{tabular}{|cc|}
\hline Prioridade & Tipo de Projeto / Restrições \\
\hline 1 & Projetos corporativos da matriz \\
2 & $\begin{array}{c}\text { Projetos que atendam requisitos } \\
\text { legais/fiscais } \\
3\end{array}$ \\
4 & Projetos de melhoria de eficiência e \\
redução de custos & Disponibilidade de recursos \\
\hline
\end{tabular}

Fonte: Elaborado pelo Autor a partir da entrevista com o ClO da Empresa 4 (2016).

O processo de seleção destes projetos é guiado por essas prioridades, estabelecendo um processo de funil, tal como proposto por Clark e Wheelwright (1993). Este processo é dirigido pelo ClO, que apresenta a seleção de projetos escolhidos, junto com as justificativas de cada um deles para avaliação da gerência sênior e unidades de negócios.

O processo pode ser revisado, normalmente com periodicidade anual, porém necessidades especiais de negócios podem direcionar a alteração de prioridades na implantação de projetos. 


\section{Caso 5}

O caso 5 tem como objeto de pesquisa a área de TI da AES Eletropaulo, distribuidora de energia elétrica para 24 munícipios da grande São Paulo, sendo a maior da América Latina, com cerca de 17 milhões de clientes. A empresa presta serviço ao principal complexo industrial e financeiro do Brasil, contando com uma força de trabalho de mais de 5.500 funcionários próprios e cerca de 10.000 funcionários terceirizados. A AES Eletropaulo é responsável por 34,3\% da energia elétrica consumida no estado de São Paulo e 10,5\% da energia fornecida no Brasil. O Grupo AES é ainda composto por quatro empresas no Brasil, sendo duas distribuidoras de energia elétrica (AES Eletropaulo e AES Sul) e duas geradoras (AES Tietê e AES Uruguaiana). A AES Eletropaulo e AES Tietê fazem parte do ISE. O grupo está presente em outros 26 países, contando com cerca de 28 mil funcionários.

A área de TI da AES atende ao grupo como um todo e tem como característica a terceirização de todos os serviços que envolvem hardware (data center, impressoras e microcomputadores). A empresa atua na governança destes serviços, nas demandas das áreas de negócios e ainda no atendimento de requisitos legais e de regulamentação do setor elétrico. Os projetos de TI, objeto do estudo do caso 5 , são empreendidos para oferecer suporte para as áreas de negócios. A seleção de projetos deve estar em linha com o plano estratégico e de sustentabilidade.

A avaliação da seleção da carteira de projetos é realizada anualmente, quando se decidem sobre os projetos que serão realizados no ano seguinte, sendo avaliado ainda o período de quatro anos subsequentes. Nestes comitês, as áreas de negócios defendem os projetos que desejam ser incluídos na carteira, contando com o suporte tecnológico da área de TI. As áreas de negócios apresentam o plano de negócios (business plan) para cada projeto candidato e os mesmos são selecionados pelo critério de avaliação de custo e benefício (normalmente quanto ao retorno e prazo do retorno de investimento). Os projetos que apresentam os melhores indicadores têm prioridade na seleção e o processo tem características de funil. 
Candidatos a projetos que envolvem questões legais e fiscais, assim como projetos com critérios regulatórios, são excluídos da análise e executados sempre. Segundo o entrevistado da área de $\mathrm{Tl}$, o setor elétrico é sujeito a uma série de regulamentações que devem ser atendidas. Em função do processo de terceirização de ativos e serviços, a AES não realiza projetos de atualização de ciclo de vida de produtos.

Um importante aspecto no processo de seleção de projetos é que a primeira etapa estabelece as bases dos projetos que serão executados. Nessa etapa a área de TI tem papel de suporte. Uma vez tendo sido incluído na carteira de projetos, a área de $\mathrm{TI}$ assume o papel de definir a melhor solução técnica para atender à demanda. De acordo com o gerente de infraestrutura de $\mathrm{TI}$, a área de negócios define "o que" e a área de TI define "como" realizar os projetos. Um exemplo citado foi a decisão de criar uma nova empresa no grupo, decisão tomada pelo comitê executivo. A partir deste ponto, a área de $\mathrm{TI}$ define como devem ser realizados os projetos específicos para viabilizar a nova empresa.

Mensalmente ocorre uma reunião do comitê executivo de $\mathrm{TI}$, do qual fazem parte os vice-presidentes, diretores e gerentes das áreas de negócios e ainda os gestores de TI. Esta reunião avalia a evolução dos projetos, tomando decisões quanto às prioridades e eventuais postergações. Neste comitê são tratadas também necessidades urgentes, que podem requerer projetos ainda dentro do período do ano. Cancelamentos de projetos podem também ocorrer, entretanto o entrevistado não se lembrou de nenhuma ocasião em que isso tenha acontecido.

\section{Caso 6}

A área de TI da CCR é objeto de estudo do caso 6. O grupo atua em diferentes segmentos, foi fundado em 1998 e está presente em quatro países da América Latina, contando com cerca de 8 mil funcionários no Brasil. O Grupo CCR é composto por dez empresas que atuam como concessionárias de rodovias, quatro empresas que atuam na mobilidade urbana, além de quatro empresas que atuam na área de serviços. O Grupo CCR administra ainda três aeroportos localizados em 
Quito (Equador), Curaçao e San José (Costa Rica). O negócio que começou com a concessão de rodovias (sendo CCR a sigla para Companhia de Concessões Rodoviárias) expandiu-se para outras áreas.

Especificamente para a área de $\mathrm{Tl}$, uma das empresas que compõe o grupo, a CCR EngelogTec, é responsável por prestar serviços especializados de TI para as demais, além de atuar também com automação e controle, envolvendo infraestrutura, solução de arrecadação, sistemas, solução ITS (Intelligent Transport System) e soluções para mobilidade urbana. A EngelogTec tem assim uma postura híbrida, pois pela perspectiva das demais empresas, os serviços prestados podem ser considerados como terceirizados, porém, no âmbito do grupo, não enfrentam concorrência externa. A EngelogTec dispõe de seu próprio data center, de porte médio, e também é a responsável por prover equipamentos de usuários para todas as empresas do grupo.

A CCR apresenta um processo estruturado para a escolha de seus projetos de $\mathrm{TI}$, objeto de estudo deste caso. As demandas das áreas de negócios podem surgir a partir dos seguintes direcionadores:

- Análise de histórico;

- Demandas das unidades de negócio, que geram projetos específicos, que podem ser para revitalização de equipamento ou agregação de valor;

- Demandas das unidades de negócio, que após análise pela área de TI são verificadas como atendendo mais de uma empresa do grupo e são conhecidos como projetos multi-empresa;

- Pela avaliação do planejamento estratégico, que beneficia todas as empresas do grupo e é chamado de projeto corporativo;

Os candidatos são divididos em projetos que atendem à obrigação legal ou contratual, que são sempre executados; projetos que proporcionem ganhos de produtividade e projetos que automatizem processos manuais.

Segundo o entrevistado da área de $\mathrm{Tl}$, a avaliação dos candidatos é feita de forma bastante ampla, começando nas unidades de negócios, que definem suas necessidades junto com o representante de TI. A necessidade de atendimento de obrigações legais contratuais e ainda a necessidade de revitalização de vida útil é acrescentada pela TI corporativa e esse conjunto de candidatos passa a ser o 
portfólio da unidade. O portfólio preparado pela TI corporativa é devolvido para a unidade de negócios, que valida e realiza uma segunda análise de priorização. Este portfólio revisado volta para a TI corporativa, que separa os projetos corporativos e multi-empresa e estes são apresentados para o comitê corporativo, que avalia os investimentos e recursos necessários. Os projetos aprovados por esse comitê voltam para as unidades de negócios, que os incluem em seu planejamento de negócios.

O processo é realizado anualmente, com uma visão de cinco anos. Mensalmente é avaliada a tendência dos projetos em execução, com previsão de dois anos. Caso ocorram desvios, as áreas de negócios validam as mudanças, que são controladas por um PMO corporativo de TI.

\section{Discussão dos Resultados}

Todos os casos pesquisados apontaram um processo estruturado para a seleção de seus candidatos a projetos, sendo que um critério comum a todos é a necessidade dos candidatos estarem alinhados aos objetivos estratégicos da organização, confirmando os estudos de Cooper et al. (1999), Ghasemzadeh \& Archer (2000) e Rabechini Jr et al. (2005). Outro critério comum em todos os casos é a análise de modelos financeiros (Cooper et al., 1999), como análises de retorno de investimento (em valores monetários e tempo de amortização do investimento) e avaliação custo benefício.

Os casos deste estudo analisam as demandas de projetos junto com suas áreas usuárias e ainda fazem suas avaliações de portfólio de projetos com periodicidade anual, com exceção do caso 2 , que as faz mensalmente. A avaliação da evolução da carteira de projetos é feita com periodicidade mensal. Um fator apontado em cinco dos seis casos como sendo avaliado na seleção de projetos e que não foi verificado na pesquisa bibliográfica diz respeito a projetos para atender demandas legais, de regulamentação ou ainda de contrato.

Nenhum caso estudado respondeu positivamente quando perguntado se utiliza 
um processo de análise hierárquica como a AHP (Liu et al., 2011; Padovani et al., 2010; Padovani et al., 2008; Saaty, 1988; Saaty, 2007). Os processos, em todos os casos pesquisados, assemelham-se ao modelo de funil, conforme Clark e Wheelwright (1993).

Foi também citado que o processo de aprovação segue o modelo de pirâmide, ou seja, quanto maior o valor, investimento, abrangência e complexidade, por exemplo, a aprovação é avaliada em níveis mais altos na hierarquia da organização. Essa característica foi comentada de forma mais intensa nos casos 2 e 6 (Johnson Controls e CCR).

Em apenas um caso estudado (Empresa 3), houve menção a considerar riscos em sua análise de seleção de portfólio de projetos, conforme citado por Ghasemzadeh \& Archer (2000).

A Tabela 4 aponta características e critérios verificados na literatura (Cooper et al., 1999; Ghasemzadeh \& Archer, 2000) e outros citados pelas empresas pesquisadas.

\section{Tabela 4}

Características e critérios de análise de portfólio

\begin{tabular}{|c|c|c|c|c|c|c|c|c|c|c|c|c|}
\hline Caso & $\begin{array}{c}\text { Modelo } \\
\text { de } \\
\text { avaliação }\end{array}$ & $\begin{array}{l}\text { Categori- } \\
\text { zação de } \\
\text { projetos }\end{array}$ & $\begin{array}{c}\text { Alinhamento } \\
\text { Estratégico }\end{array}$ & $\begin{array}{c}\text { Análise de } \\
\text { modelo } \\
\text { financeiro }\end{array}$ & $\begin{array}{l}\text { Demanda } \\
\text { junto às } \\
\text { áreas } \\
\text { usuárias }\end{array}$ & $\begin{array}{c}\text { Periodi- } \\
\text { cidade }\end{array}$ & $\begin{array}{c}\text { Demanda } \\
\text { Legal } \\
\text { Contratual }\end{array}$ & $\begin{array}{l}\text { Avaliação } \\
\text { de Riscos }\end{array}$ & $\begin{array}{c}\text { Complex } \\
\text { dade }\end{array}$ & $\begin{array}{l}\text { i- Capacidade } \\
\text { de recursos }\end{array}$ & $\begin{array}{c}\text { Análise } \\
\text { ciclo de } \\
\text { vida }\end{array}$ & $\begin{array}{c}\text { Projetos } \\
\text { Multi } \\
\text { área }\end{array}$ \\
\hline 1 & Funil & Não utiliza & Sim & Rol & Sim & Anual & Sim & Não & Sim & Sim & Não & Não \\
\hline 2 & Funil & 4 níveis & Sim & $C \times B$ & Sim & Mensal & Não & Não & Sim & Não & Não & Sim \\
\hline 3 & Funil & 3 níveis & Sim & Rol & Sim & Anual & Sim & Sim & Não & Não & Sim & Sim \\
\hline 4 & Funil & Não utiliza & Sim & $C \times B$ & Sim & Anual & Sim & Não & Não & Sim & Não & Não \\
\hline 5 & Funil & Não utiliza & Sim & Rol e $C \times B$ & Sim & Anual & Sim & Não & Não & Não & Não & Não \\
\hline 6 & Funil & 3 níveis & Sim & $\begin{array}{l}\text { Análise de } \\
\text { orcamento }\end{array}$ & Sim & Anual & Sim & Não & Não & Sim & Sim & Sim \\
\hline
\end{tabular}

Fonte: Elaborado pelo Pesquisador a partir das entrevistas com os gestores de TI das empresas (2016). Legenda: Rol - Retorno do Investimento; C x B - Análise custo versus benefício.

A Figura 1 representa, no modelo de funil, as etapas da seleção da carteira de projetos de TI. 


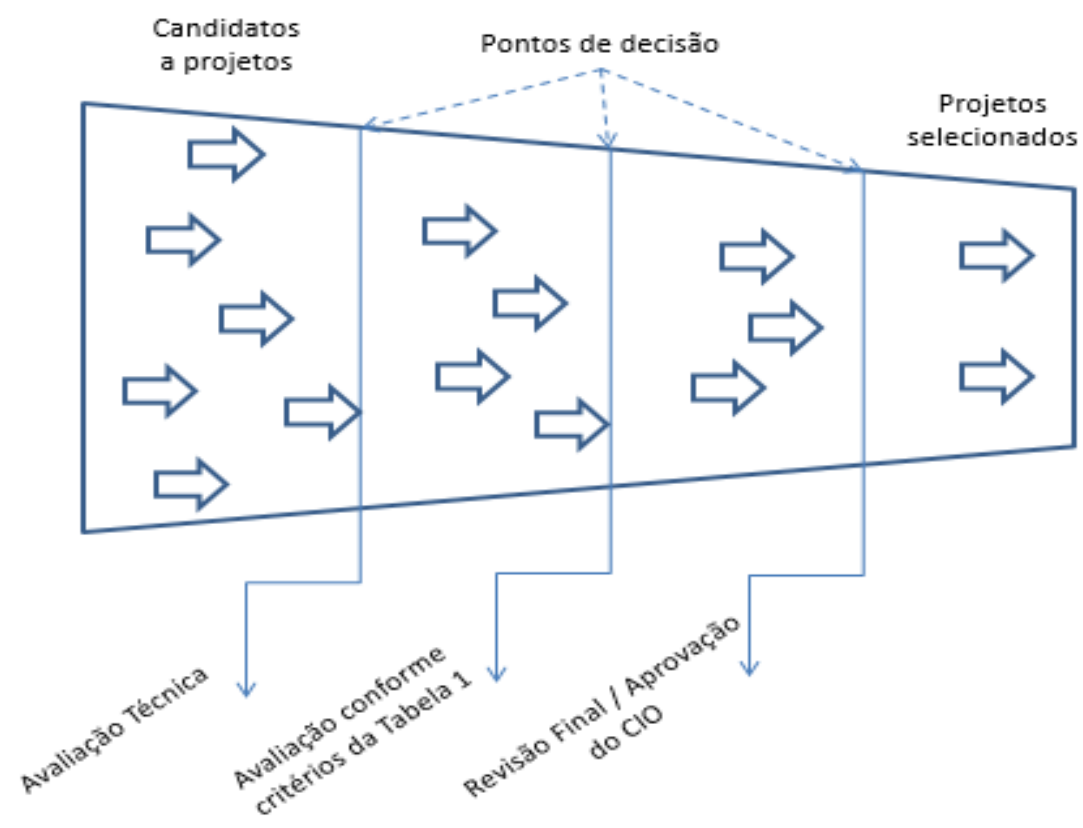

Figura 1

Funil de seleção de projetos de TI

Fonte: Elaborado pelo Pesquisador a partir de Ganguly (1999), conforme citado em Gavira et al., (2007).

De acordo com os entrevistados da área de $\mathrm{Tl}$, a avaliação técnica na primeira fase não necessariamente restringe candidatos, mas os apresenta para a segunda fase já com indicadores de viabilidade. No segundo ponto de decisão, os projetos aprovados são avaliados conforme os critérios indicados na Tabela 4, como por exemplo: confirmação da aderência ao alinhamento estratégico, análise de modelos financeiros, capacidade de recursos, etc.

As limitações deste estudo estão centradas na metodologia utilizada. A confirmação da eficiência das características encontradas em cada caso estudado precisa ser investigada junto ao cliente. Para que isso ocorra, e complemente o estudo realizado neste artigo, indicamos a realização de uma pesquisa futura com métodos quantitativos, avaliando também a percepção dos clientes destas empresas, realizando assim uma analogia com as características aqui levantadas, possibilitando, desta maneira, um julgamento sobre os processos de cada caso.

Outra limitação do estudo foi não ter levado em consideração o conhecimento sobre a área. Sendo assim, uma possível pesquisa futura pode contribuir com esta atual limitação. A aplicação de uma pesquisa utilizando-se do método de pesquisa 
survey com empresas que tenham a área de $\mathrm{TI}$ estruturada, ou mesmo com funcionários destas áreas, pode promover o conhecimento e contribuir com a investigação que foi proposta neste estudo.

\section{Conclusão}

Nos casos analisados neste trabalho, o processo de seleção de projetos de TI utiliza o modelo de funil, sendo a avaliação das características e dos critérios técnicos o primeiro ponto de decisão deste processo. No segundo ponto de decisão, os candidatos já são apresentados com soluções técnicas, orçamentos, complexidade e necessidade de recursos, principalmente, quando são então avaliados com relação a outros critérios.

As organizações que foram objeto deste estudo são de grande porte, possuindo áreas de TI estruturadas e que atuam sob princípios de governança corporativa. Não foram avaliadas organizações de pequeno/médio porte para efeito de comparações. Porém foram analisadas dentro do objetivo de levantar características da área de TI.

As contribuições deste estudo se fundamentam na descrição das características de portfólio de projetos na literatura e a comparação delas com a gestão prática dos projetos de TI. O estudo de múltiplos casos também pode ser visto como contribuição deste artigo, pois, uma vez realizado o levantamento, pode servir como comparação para empresas que possuem tais processos ou pretendem aprimorá-los. Este estudo também desperta ideias para novas investigações na área de TI, podendo assim contribuir para o avanço das pesquisas da temática de gestão de portfólios e projetos, levando em consideração o funil de inovação de Clark e Wheelwright (1993).

\section{Referências}

Albertin, A. L. (2001). Valor estratégico dos projetos de tecnologia da informação. RAE - Revista de Administração de Empresas, 41(3), 42-50.

Albertin, A. L., \& Albertin, R. M. D. M. (2008). Tecnologia de Informaçăo e 
Desempenho Empresarial no Gerenciamento de seus Projetos: um Estudo de Caso de uma Indústria. RAC Curitiba, 12(3), 599-629.

Archer, N. ., \& Ghasemzadeh, F. (1999). An integrated framework for project portfolio selection. International Journal of Project Management, 17(4), 207-216.

Brusamolin, V., \& Moresi, E. (2008). Narrativas de histórias : um estudo preliminar na gestão de projetos de tecnologia da informação. Ciência Da Infomação, Brasília, $37(1), 37-52$.

Carvalho, M. M., \& Rabechini Jr., R. (2015). Fundamentos em Gestão de Projetos (4a ed.). São Paulo: Atlas.

Clark, K. B., \& Wheelwright, S. C. (1993). Managing new product and process development:text and cases. New York: The Free Press.

Cooper, R. G. (2008). Perspective: The Stage-Gate. Journal of Production and Innovation Management, 25, 213-232.

Cooper, R. G., Edgett, S. J., \& Kleinschmidt, E. J. (1999). New Product Portfolio Management: Practices and Performance. Journal of Production and Innovation Management, 6782(99), 333-351.

Garcez, M. P., \& Maccari, E. A. (2015). Metodologia de avaliação do portfólio de projetos de p\&d pelo valor presente ajustado ao risco - Um estudo de caso na indústria petroquímica. Revista de Gestão e Projetos - GeP, 7(2), 42-53.

Gavira, M. de O., Ferro, A. F. P., Rohrich, S. S., \& Quadros, R. (2007). Gestão da inovação tecnológica: uma análise da aplicação do funil de inovação em uma organização de bens de consumo. Revista de Administração Mackenzie, 8(1), 77-107.

Ghasemzadeh, F., \& Archer, N. P. (2000). Project portfolio selection through decision support. Decision Support Systems, 29(1), 73-88.

Gil, A. C. (2012). Métodos e técnicas de pesquisa social (6a ed.). São Paulo: Editora Atlas.

Henderson, J. C., \& Venkatraman, N. (1993). Strategic alignment: Leveraging information technology for transforming organizations. IBM Systems Journal, 32(4-16).

Kerzner, H. (2009). Project Management: A systems approach to planning, scheduling and controlling (10th ed.). New York: John Willey and Sons.

Laurindo, F. J. B., Shimizu, T., Carvalho, M. M. De, \& Rabechini Jr, R. (2001). O papel da tecnologia da informação (TI) na estratégia das organizações. Gestão e Produção, 8(2), 160-179. 
Liu, K. F. R., Hsu, C., Yeh, K., \& Chen, C. (2011). Hierarchical analytic network process and its application. Civil Engineering and Environmental Systems, 28(1), $1-18$.

Molla, A., Pittayachawan, S., Corbitt, B., \& Deng, H. (2009). An International Comparison of Green IT Diffusion. International Journal of E-Business Management, 3(2), 3-23.

Nolan, R., \& McFarlan, F. . W. (2005). Information Technology and the Board of Directors. Harvard Business Review, 83(10), 96-106.

Padovani, M., Carvalho, M. M. De, \& Muscat, A. R. N. (2010). Seleção e alocação de recursos em portfólio de projetos: estudo de caso no setor químico. Gestão e Produção, 17(1), 157-180

Padovani, M., Muscat, A. R. N., Camanho, R., \& Carvalho, M. M. de. (2008). Looking for the right criteria to define projects portfolio: Multiple case study analysis. Product: Management \& Development, 6(December), 127-134.

PMSURVEY. (2013). Resultados da edição 2013. Recuperado em 20/10/2016 de www.pmsurvey.org

Rabechini Jr, R., Maximiano, A. C. A., \& Martins, V. A. (2005). A adoção de gerenciamento de portfolio como uma alternativa gerencial: o caso de uma empresa prestadora de serviço de interconexão eletrônica. Revista Produção, 15(3), 416-433.

Reyck, B. De, Grushka-cockayne, Y., Lockett, M., Calderini, S. R., Moura, M., \& Sloper, A. (2005). The impact of project portfolio management on information technology projects. International Journal of Project Management, 23, 524-537.

Saaty, T. L. (1988). What is the analytic hierarchy process? In G. Mitra (Ed.), Mathematical Models for Decision Support (1st ed., pp. 109-121). Berlin: Springer-Verlag.

Saaty, T. L. (2007). Time dependent decision-making; dynamic priorities in the AHP/ANP: Generalizing from points to functions and from real to complex variables. Mathematical and Computer Modelling, 46(7-8), 860-891.

Schneider, R. M., Barbosa, J. G. P., Bouzada, M. A. C., \& Gonçalves, A. A. (2016). A influência de fatores organizacionais na gestão de projetos de tecnologia da informação (TI). Revista Gestão \& Tecnologia, 16(1), 157-183.

Shenhar, A. J. (2004). Strategic Project Leadership Toward a strategic approach to project management. R\&D Management, 34(5), 569-578.

Shenhar, A. J., \& Dvir, D. (2010). Reinventando gerenciamento de projetos: a abordagem diamante ao crescimento e inovação bem-sucedidos (1st ed.). São Paulo: M.Books. 